\section{Desplazados legales o ilegales: una mirada desde los procesos extractivos en Colombia y contexto general de algunos países latinoamericanos}

Anuario Latinoamericano Ciencias Políticas y Relaciones Internacionales vol. 3, 2016

pp. 241-273

DOI: $10.17951 /$ al.2016.3.241

\section{Legally or illegally displaced persons: a view from the extractive processes in Colombia and general context of some Latin American countries}

\author{
Angie Betancur Vargas \\ UNIVERSIDAD DE ANTIOQUIA, COLOMBIA \\ $\triangle$ anibetancur@hotmail.com \\ Margarita María Pérez Osorno \\ UNIVERSIDAD DE ANTIOQUIA, COLOMBIA \\ $\triangle$ margarita.perez@udea.edu.com
}

\begin{abstract}
RESUMEN
Colombia ocupa el segundo puesto en el ranking de los países con mayores tasas de desplazamiento forzado a nivel mundial, situación que se ha potencializado tras la incursión de la industria minera a lo largo y ancho del territorio nacional, convirtiendo a zonas prósperas en cuanto a recursos minerales en áreas de contiendas $y$ fuertes disputas territoriales, no sólo entre las comunidades y multinacionales, sino también entre éstas y los grupos armados al margen de la ley quienes, a la par con el gobierno, han visto en esta actividad extractiva una forma de sustento y prosperidad monetaria. El presente artículo pretende caracterizar la situación actual de Colombia ante el fenómeno del desplazamiento forzado y su relación con la incursión de la industria minera, logrando esto por medio de una revisión y análisis documental. Colombia y algunos países de Latinoamérica cuentan con el mayor número de conflictos internos por factores como la violación de derechos civiles y territoriales suscitados por la implementación de proyectos mineros en sus localidades, lo que ha ocasionado un fenómeno de movilización social a otras zonas que posibiliten la manutención de las comunidades afectadas. Generalmente, se relacionan tres características dentro de las causas de dichas migraciones: desplazamientos directos que propagan las empresas tras los estudios de impacto ambiental realizados al inicio del proyecto, movilizaciones "voluntarias" de las comunidades debido al detrimento social y ambiental de sus entornos y migraciones producidas por amenazas territoriales entre empresas y sociedad civil. Se obtiene como conclusión general que, a pesar de que las características estudiadas sobre el fenómeno del desplazamiento
\end{abstract}


forzado en zonas de extracción minera son multicausales, todas - bien sea de manera indirecta o directa - son una manifestación de la prioridad que se le ha dado a este tipo de industria por encima de los derechos humanos de las comunidades ubicadas en las denominadas zonas de interés minero energético.

PALABRAS CLAVE: desplazamiento forzado, minería, migraciones, extracción minera, conflicto territorial.

\section{ABSTRACT}

Colombia ranks second among the countries with the highest rates of forced displacement, a situation that has augmented after the incursion of the mining industry throughout the national territory, turning areas rich in mineral resources into areas of strife and strong territorial disputes, not only between communities and corporations, but also between these and armed criminal groups which, just like the government, have seen in this extractive activity a livelihood and source of income. The present article aims to characterize the current situation in Colombia regarding the phenomenon of forced displacement and its relationship with the incursion of the mining industry. It will be achieved through a documentary review and analysis. Colombia and some Latin American countries have the largest number of internal conflicts caused by factors such as the violation of civil and territorial rights arising from the implementation of mining projects. It is the source of the phenomenon of displacement of affected communities to other areas. Three characteristics are usually related with the causes of these migrations: direct movements propagated by the mining companies after the environmental impact studies conducted at the beginning of the project, "voluntary" mobilization of communities due to social and environmental detriment of their environments and migration produced by territorial threats between companies and civil society. The general conclusion is that, although the characteristics of the phenomenon of forced displacement in areas of mining are multicausal, they all - either indirectly or directly - are a manifestation of the priority given to this type industry over the human rights of the concerned communities.

KEYWORDS: forced displacement, mining, migration, territorial conflict.

\section{Introducción}

El ser humano se ha valido de sus suelos y recursos naturales como medio de subsistencia económica, cultural, política y social, y su desarrollo y progreso se ha basado en su manera de producción y relación con estos, centrándolos como la base fundamental de la subsistencia de todo tipo de especie.

Tanto Colombia como algunos países latinoamericanos son poseedores de un gran potencial de recursos ambientales y de un alto nivel de biodiversidad, territorios que durante siglos han albergado en sus entrañas un conjunto de minerales preciosos, únicos y de gran valor mercantil. Hoy en día, ocupan los primeros puestos en el ranking mundial de los principales exportadores de 
minerales preciosos como cobre, oro, litio, plata, níquel, caliza, estaño, plomo, zinc, hierro, bismuto y carbón.

Actualmente, poseer esta gran biodiversidad y abundancia natural trae como consecuencia ser merecedor de incontables licencias y permisos de explotación. Este es el caso de algunos países de Latinoamérica, entre ellos Colombia, la nación que se encuentra plagada de proyectos minero-energéticos, bajo la ilusión y promesas de riquezas y prosperidad para sus territorios, enriquecimiento que no se ha visto en ninguna de las economías propias de sus departamentos, por el contrario, solo se ha generado pobreza y destrucción, tanto ambiental como social.

La minería llega a un lugar con su promesa de generación de riquezas y empleo, pero se cuentan en millones quienes en todo el mundo pueden dar testimonio de los altos costos sociales que trae consigo: apropiación de las tierras de las comunidades locales, impactos en la salud, alteración de las relaciones sociales, destrucción de las formas de sustento y de vida de las comunidades, desintegración social, cambios radicales y abruptos en las culturas regionales, desplazamiento de otras actividades económicas locales actuales y/o futuras. (Forest Peoples Programme 2003: 8)

Según John Ruggie (exRepresentante Especial de Naciones Unidas sobre Empresas y Derechos Humanos), citado por el Grupo de Trabajo sobre Minería y Derechos Humanos en América Latina (2010), el grupo económico que cuenta con la mayor cantidad de denuncias y querellas por violaciones y quebrantos a los derechos humanos debido a procedimientos impropios e injustos es la industria minera. Generalmente, dichas denuncias están relacionadas con daños territoriales al medio ambiente, infraestructura, apropiación de tierras y violación a los derechos comunales de consulta previa.

Para dar una aproximación del contexto, tanto colombiano como latinoamericano, en cuanto a los estragos sociales generados por este tipo de actividad económica, a continuación se cita un fragmento de uno de los textos estudiados:

En América Latina son numerosos los conflictos por la resistencia de las comunidades a modelos de minería que afectan el medio ambiente y vulneran los derechos humanos. La base de datos del Observatorio de Conflictos Mineros en América Latina (OCMAL) registraba, a la fecha de elaboración del informe, cerca de 198 conflictos activos por causa de la mega minería en la región. De esos conflictos, 26 se presentaban en Argentina, 20 en Brasil, 34 en Chile, 12 en Colombia, 29 en México y 34 en Perú. (Defensoría del Pueblo de Perú, citado por Grupo de Trabajo sobre Minería y Derechos Humanos en América Latina 2010: 4)

Como se puede evidenciar, la industria extractiva minera ha dejado a su paso un conjunto de impactos sociales y ambientales en el centro y sur del
Desplazados legales o ilegales: una mirada desde los procesos extractivos en Colombia y contexto general de algunos países latinoamericanos

Angie Betancur Vargas Margarita María Pérez Osorno 
continente americano, demostrando el significado poderoso para este modo de producción de la noción de "tenencia de la tierra" como único medio de subsistencia de su labor, puesto que si no se tiene un "libre uso de esta", no se puede explotar de manera "adecuada" y "beneficiosa", y para poder adquirir un usufructo autónomo y soberano de los recursos de determinado territorio se debe garantizar que no existan asentamientos humanos que posibiliten retrocesos a este sector, bien sea de manera directa o indirecta, ya que la industria extractiva de la minería requiere el territorio de explotación libre para poder tener el mayor beneficio de los recursos. Lastimosamente, bajo este contexto, no se permite hablar del gobierno como regulador e institución a la que pueden acudir las comunidades para hacer garantía de sus derechos, puesto que es éste quien otorga los permisos de explotación a las empresas mineras y les da abrigo en sus naciones, situación que permite entrever la postura del Estado, dejando un panorama de incertidumbre social para aquellas comunidades que se ubican en zonas de "interés nacional" debido a la alta cantidad de minerales que poseen sus suelos.

Bajo este contexto, se permite hablar de un fenómeno social que obligatoriamente se presenta en todos los proyectos mineros: el desplazamiento forzado, entendiéndose este (según la ONU) como: "personas o grupos de personas obligadas a huir o abandonar sus hogares o sus lugares habituales de residencia, en particular como resultado de un conflicto armado, situaciones de violencia generalizada, violación de los derechos humanos" (Mendoza 2012: 4).

Un artículo noticiario publicado en el periódico "El Mundo"(2014) argumenta que el desplazamiento forzado es un tema crucial en América Latina, con más frecuencia en países como Honduras, México y especialmente en Colombia, nación que ocupa el segundo lugar en el ranking mundial después de Siria. En Colombia, este fenómeno empezó en 1960 y se calcula que cerca del $12 \%$ de su población nacional se encuentra en condición de desplazamiento, teniéndose como principales causas los enfrentamientos armados entre grupos al margen de la ley y el gobierno, la violencia sexual, la extorsión y disputas territoriales.

Al 31 de diciembre del 2014, los territorios con mayor número de casos registrados fueron: Siria, 7,6 millones; Colombia, seis millones; Irak, 3,3 millones; Sudán, 3,1 millones, y la República Democrática del Congo con 2,56 millones. ("Semana" 2015)

Según “Semana”(2015), Colombia cuenta con 6,044,200 de desplazados, y los departamentos que más padecen de esta problemática son Chocó, Valle del Cauca y Nariño, situación que se torna más preocupante al descubrir que el $63 \%$ de este grupo poblacional vive por debajo del umbral de pobreza y el 33\% restante en escenarios de extrema pobreza, lo que refleja la carencia de apoyo institucional en cuanto al soporte y ayuda para el restablecimiento de sus vidas. 
Por lo anterior, se hace indispensable, pues, caracterizar la situación actual de Colombia ante el fenómeno del desplazamiento forzado y su relación con la incursión de la industria minera, especialmente tras la llegada del denominado "boom minero-energético".

En el presente documento, se desglosará esta problemática, teniendo en cuenta una serie de categorías que permitirán el abordaje del objeto central de estudio. En primera estancia, se discutirá por qué la migración forzada es un fenómeno que se potencia tras la incursión de proyectos mineros. Posteriormente, con el fin de brindar una aproximación al contexto latinoamericano, se evidenciarán una serie de casos que patentizan dicho fenómeno en algunos de sus países. Finalmente, se enmarcará el contexto colombiano, siendo importante esta nación en el abordaje del tema, ya que ocupa el segundo lugar a nivel mundial en cuanto a sus cifras de migraciones, situación que se ha visto potencializada tras la incursión de la minería en sus territorios.

\section{Metodología}

Para caracterizar la situación actual de Colombia ante el fenómeno del desplazamiento forzado y su relación con la incursión de la industria minera, se llevó a cabo una revisión y análisis documental, empleándo un método de investigación cualitativo y consultando diversas fuentes bibliográficas centradas en el tema objeto de estudio, tales como: boletines informativos, libros, artículos de investigación y documentos electrónicos, que fueron respectivamente sistematizados y analizados.

Este artículo de difusión se elaboró en dos fases: la primera de énfasis investigativo, la cual consistió en la consulta y elección de los documentos clave en el marco del tema central de estudio, y la segunda de énfasis analítico, la cual se basó en la confrontación, calidad y valoración de la información obtenida en el primer ciclo, llevándose a cabo de la siguiente manera: una vez realizada la lectura de los documentos obtenidos en la primera fase, estos pasaron por un proceso de valoración de la calidad de la búsqueda a través de la consolidación de la información en matrices bibliográficas, las cuales poseían una serie de apartados, permitiendo con esto valorar la pertinencia de la información captada. Estos estaban compuestos de los siguientes numerales: tema central del documento, nivel de importancia respecto al objeto de estudio, información a tener en cuenta y significancia temática.

Para proceder a la escritura de los resultados con base a la indagación obtenida, se consolidaron tres categorías de información, las cuales permitieron tener una mayor contextualización y acercamiento al tema objeto central de estudio:

1. El desplazamiento forzado: ¿un fenómeno potencializado tras la incursión de la industria minera?
Desplazados legales o ilegales: una mirada desde los procesos extractivos en Colombia y contexto general de algunos países latinoamericanos

Angie Betancur Vargas Margarita María Pérez Osorno 
2. Contexto actual de algunos países de América Latina frente al desplazamiento forzado y su reciprocidad ante el aumento de la incursión del sector minero en sus territorios.

3. Entre la turbación y el anhelo: el sector minero en el contexto colombiano y su relación con el despojo de tierras, migraciones y desplazamiento forzado. Esta categoría se consolidó, a su vez, en dos subcategorías más, con el fin de dar mayor profundidad al tema de estudio: casos de desplazamientos voluntarios a causa del accionar minero liderado por multinacionales de dicho sector, como también casos de desplazamientos voluntarios a causa del accionar minero liderado por multinacionales de dicho sector y grupos armados al margen de la ley.

\section{El desplazamiento forzado: ¿un fenómeno potencializado tras la incursión de la industria minera?}

Según la Organización de las Naciones Unidas y el Centro de las Naciones Unidas para los Derechos Humanos (s.f.), los desplazamientos forzados pueden tener origen en varias causas: pérdida o degradación del medio ambiente, sublevaciones públicas, desastres antrópicos o naturales, conflictos tanto internos como externos, violencia intrafamiliar o territorial e incluso las condiciones inadecuadas en cuanto a calidad de vida.

$\mathrm{Al}$ analizar las implicaciones generadas por la incursión de la minería a determinado territorio, se puede evidenciar rápidamente que este tipo de proyectos generan una serie de transformaciones en las comunidades donde se llevan a cabo, bien sea a nivel medioambiental, cultural, productivo o en la dinámica social, lo que permite dilucidar y relacionar de manera directa este tipo de actividad con la generación de desplazamiento en dichos poblamientos. Al examinar las causas del fenómeno migratorio, mencionadas en el párrafo anterior, y comparar las consecuencias generadas por el desarrollo de esta industria, se puede notar que ambas tienen una relación colateral: es indiscutible que tras la pérdida de la calidad de vida en un determinado territorio, debido al detrimento de sus recursos naturales, se originan debilitamientos en el tejido social y movilizaciones de estas colectividades con el fin de hallar mejores condiciones de vida y oportunidades laborales.

Autores como Blanco y el Grupo de Trabajo sobre Minería y Derechos Humanos en América Latina argumentan que existen ciertas diferencias en cuanto a los procesos de migración generados por la incursión de proyectos mineros en los territorios, sin embargo, reconocen que, a pesar de existir distinciones en cada proceso de desplazamiento, todos tienen como eje de partida la irrupción de esta actividad en los entornos de las comunidades.

Según Blanco (2000), existen tres tipos de migraciones: “espontáneas, dirigidas y forzadas". En el caso de las dos primeras, la persona que migra lo hace de manera voluntaria y en el tercero, no solo este proceso se realiza bajo 
coacción, sino también con la incertidumbre de desconocer el lugar de llegada. Blanco asegura que estas migraciones se promueven tras la degradación de uno o varios de estos tres contextos: ecológico, económico y político, siendo en el primer y tercer caso el origen de las migraciones dadas bajo presión. Sin embargo, señala que tanto las migraciones económicas como forzadas se pueden generar bajo un contexto de miseria de la población, ya que este tipo de condiciones obliga a las comunidades a partir de su lugar de origen tras mejores condiciones de vida.

Esto no discrepa mucho de las características de este fenómeno estudiadas por el Grupo de Trabajo sobre Minería y Derechos Humanos en América Latina (2010), quienes afirman que algunos proyectos mineros ejecutados en esta parte del continente han generado alteraciones territoriales en varios asentamientos, creando una serie de desplazamientos forzados, y sus singularidades se pueden diferenciar de la siguiente manera:

- Migraciones propiciadas tras los resultados dados por los estudios de impacto ambiental que cada proyecto debe realizar antes de llevar a cabo la extracción minera.

- Evacuación "voluntaria” de las comunidades: debido a los estragos ambientales generados por este tipo de proyectos, estas deben migrar a zonas que les permitan tener mejores condiciones en cuanto a calidad de vida.

- El tercer tipo de desplazamiento se efectúa por la presión de las empresas a la misma población, con el fin de sustituir sus procesos artesanales de extracción minera por los establecidos por el mismo proyecto extractivo.

Como se puede evidenciar, a pesar de que los estudiosos sobre el tema reconocen que existen tres características claves en el proceso de desplazamiento forzado generado por proyectos mineros (mencionadas en los párrafos anteriores), se puede llegar a un mismo postulado: cualquier tipo de desplazamiento que se genere en un entorno donde esté emergiendo la minería tiene como consecuencia central la implementación de proyectos extractivos en su territorio, ya sea que las empresas demuestren que deben las comunidades aledañas abandonar o no sus lugares de origen o las mismas poblaciones "decidan" partir debido a las propias implicaciones sociales, ambientales, culturales y económicas que trae consigo el desarrollo de proyectos mineros en sus hábitats.

Debido a la significancia que este fenómeno tiene y a su relación directa con la extracción minera, se hace importante diferenciar los riesgos y las implicaciones a las cuales se ven enfrentadas las comunidades migrantes tras la ocupación de este tipo de actividad en sus territorios, ya que indiscutiblemente se genera una violación a los derechos humanos de este tipo de poblaciones. Según Michael Cernea, sociólogo investigador para el Banco Mundial, (AGFE, citado por Tejada 2010) existen seis riesgos implícitos en todos los procesos de desplazamiento a causa de los proyectos de desarrollo:

- Pérdida de la tierra: este proceso tiende a generar "alineación y descenso en el estatus", ya que se pierde el espacio cultural, sistemas de producción, modos de sustento y viviendas.
Desplazados legales o ilegales: una mirada desde los procesos extractivos en Colombia y contexto general de algunos países latinoamericanos

Angie Betancur Vargas Margarita María Pérez Osorno 
- Pérdida de acceso a la propiedad común: esto trae consigo afectaciones en cuanto al sustento e ingreso monetario de las comunidades.

- Pérdida de trabajo: en condiciones de desplazamientos, existe un riesgo alto de pérdida de empleo por parte de las comunidades afectadas.

- Marginalización: este riesgo se genera tras la entrada de las comunidades afectadas al empobrecimiento, ya que no tienen manera de sostenerse económicamente.

- Inseguridad alimentaria: esto concibe, a su vez, mayores tasas de morbilidad y mortalidad, ya que las formas de cultivo de las tierras se alteran, tras el ingreso de los mismos proyectos mineros.

- Desintegración social: cuando se forman procesos de desplazamiento, se ven afectados los sistemas productivos, las relaciones de comercio y demás esferas de organización comunitaria.

Como se puede estimar, el fenómeno de desplazamiento forzado a causa de la minería es una situación que debe coexistir con otras implicaciones sociales que se forjan tras el desarrollo de la actividad minera, lo que indica que este contexto no se da netamente por un solo motivo, sino también que es multicausal. No solamente son las empresas mineras las que llegan a los territorios a expropiarlos directamente de sus recursos, sino también es todo el proceso que se da en torno a esta labor, es decir, existen riesgos sociales que se derivan directamente del desarrollo de esta industria, que repercuten en las características comunitarias de los territorios y que generan un debilitamiento en su estructura, lo que ocasiona que estas poblaciones busquen mejores entornos para subsistir, ya que es natural del ser humano, alcanzar su bienestar tanto físico como mental y social.

Sin embargo, cabe destacar, por lo estudiado a lo largo del documento, otras causas que originan el fenómeno de desplazamiento forzado, las cuales indican que este no solamente se da tras la incursión de la minería en un territorio, pero sí es un factor que se relaciona directamente con los sectores considerados de interés minero-energético. El siguiente fragmento narra las causas del desplazamiento colombiano:

Amenazas de muerte, mal trato psicológico, amenazas de reclutamiento forzado, enfrentamientos armados, muerte de familiar a raíz de conflicto, desaparición de familiar, robo de bienes por un actor armado, malos tratos físicos, malos tratos para exigir colaboración, reclutamiento forzado y negar o restringir acceso a bienes de supervivencia. (Vanguardia.com 2009)

Resulta evidente que estas causas se asocian a un contexto minero, ya que la disputa por territorio puede dar cabida a cualquiera de estas circunstancias, lo cual se ha evidenciado en la literatura y diferentes medios de comunicación, escenario que permite dilucidar que, en la mayoría de los casos, las comunidades cercanas a proyectos mineros, de manera directa o no, deben abandonar sus territorios de origen por la insostenibilidad que representa la ejecución de proyectos mineros para su supervivencia. 


\section{Contexto actual de algunos países de América Latina frente al desplazamiento forzado y su reciprocidad ante el aumento de la incursión del sector minero en sus territorios}

Con el fin de tener una noción de las implicaciones sociales que ha tenido el desarrollo de esta actividad en el contexto colombiano, se hace importante identificar, a su vez, la situación que padecen hoy en día algunos países de América Latina, permitiendo así un acercamiento mayor al problema y una dimensión más acertada de lo que significa este fenómeno.

El incremento de la inversión minera en América Latina ha representado un punto de partida para el crecimiento de las economías propias de dichos países, a tal punto de convertir esta parte del continente en el eje de inversión de compañías extractivas de carácter internacional, lo que ha generado un contexto de disputas territoriales entre los nativos de zonas de interés para esta industria, ambientalistas, gobiernos y multinacionales. En una publicación realizada en el Clarin.com en el año 2012, se esgrime que uno de los principales motivos de dichas pugnas son la carencia del debido cumplimiento a la normatividad, a la par de que se cuenta con un marco legal débil y poco estructurado.

Ese escenario complejo se combinó con legislaciones permisivas que facilitaron el avance de las multinacionales que en numerosos casos ignoraron barreras y normativas ambientales. Así, miles de proyectos de extracción mineral se instalaron desde México hasta la Patagonia. El proceso fue de modo tal aluvional que la región quedó en la cima del ranking de inversión minera del planeta. Con este panorama, la fiebre del oro se transformó en la clave para acomodar economías debilitadas y las protestas ecologistas se volvieron muy molestas para los planes de varios gobiernos. (Clarin.com 2012)

Hace un par de décadas, los gobiernos latinoamericanos han apostado al boom de la industria minera como medio de salida del subdesarrollo, para encamar la lista de países industrializados del mundo, situación que deja un sinsabor en los territorios poseedores de altos niveles de recursos mineros, puesto que se han convertido en el blanco no solo de las empresas generadoras de proyectos extractivos, sino también de los propios gobiernos, lo que ha generado un panorama de inestabilidad social, sin contar con los grandes estragos ambientales que deja a su paso este tipo de economía. América Latina, al apuntarle a la minería como medio de desarrollo económico, no ha generado lo que inicialmente se pensaba, que era el crecimiento industrial de sus países, por el contrario, se ha obtenido un debilitamiento territorial en cuanto a sus dinámicas culturales, sociales, políticas, ambientales y económicas, ya que, al permitir el ingreso a sus naciones de este modo de producción, se suscitó
Desplazados legales o ilegales: una mirada desde los procesos extractivos en Colombia y contexto general de algunos países latinoamericanos

Angie Betancur Vargas Margarita María Pérez Osorno 
que otros Estados con mayores índices de poder se adueñaran de sus recursos y debilitaran sus procesos internos.

Un ejemplo claro de decaimiento de la dinámica social interna de una nación a causa de la implementación de proyectos de extracción minera en sus territorios se da bajo el proceso de desplazamiento forzado y/o migración, contexto del cual, el sur y centro del continente americano no están muy alejados:

Entre agosto de 2014 y noviembre de 2015, a lo largo de América han ocurrido cuatro desastres mineros que han causado desplazamientos forzosos de población, degradación ambiental, afectaciones graves a la salud e incluso la muerte de personas (...) El principal argumento esgrimido por las empresas mineras ha sido que estos eventos han sido accidentes, desastres naturales ofallos técnicos de las construcciones. (Rinde cuentas 2015)

Según Chaparro y Salgado (2005), el desplazamiento forzado es un proceso que se ha dado en varios países de mundo y se ha incrementado de manera alarmante. Las principales causas que generan este fenómeno son: violencia, conflictos por la tierra, áreas de zonas rurales convertidas en "desiertos" debido a los procesos antrópicos, pobreza rural, crecimiento de la población, escasez de recursos, entre otros; situación que se agrava si se le adiciona los procesos de deuda externa, técnicas de intercambio desfavorables con países desarrollados, etc., dando como resultado un contexto sociopolítico poco equilibrado, lo que repercute en la estabilidad social y desarrollo de un país.

Es importante, pues, definir lo que significa el proceso de migración, entendiéndose este según la Organización Internacional para las Migraciones (2006) como un desplazamiento de determinados grupos de personas en el que se evidencia la presión, comprendiendo la intimidación a la vida y su conservación, lo que se puede generar por causas naturales o humanas: "Por ejemplo, movimientos de refugiados y de desplazados internos, así como personas desplazadas por desastres naturales o ambientales, desastres nucleares o químicos, hambruna o proyectos de desarrollo".

Como se puede denotar, el desarrollo de la extracción minera trae consigo un debilitamiento de la estructura interna de los territorios, ya que estos se basan muy fuertemente en las maneras de producción que posibilitan sus tierras. $\mathrm{Al}$ no existir medios naturales que soporten el desarrollo de dichas comunidades, estas se ven forzadas a migrar. Dentro de las principales causas que se dan en estos procesos de desplazamientos forzados generados por la minería están: disputas por tierras entre las empresas mineras, el Estado y la comunidad, lo que, a su vez, genera un aumento de los índices de violencia y desorden social; también se crea un incremento en los niveles de pobreza, puesto que, al reemplazar los medios de subsistencia de estas colectividades, estas se quedan sin posibilidad de adquirir ingresos monetarios, asimismo, estos territorios se ven en constante disputa por el quebrantamiento de sus derechos civiles 
y por la imposibilidad de gozar libremente de territorios sanos, tanto a nivel ambiental como económico, político y social.

En las zonas donde se llevan a cabo procesos de explotación minera, ya es común hablar de un mismo fenómeno y es sobre el desplazamiento forzado y migraciones. Tristemente los territorios más afectados tras la implementación de esta actividad son los entornos pertenecientes a campesinos, indígenas y afrodescendientes, ya que son el tipo de personas que tienden a asentarse en suelos ricos en recursos y biodiversidad, por sus medios de subsistencia, modo de vida e historia cultural, lo que genera una condición de vulnerabilidad especial en este tipo de entornos, debido a que son espacios ideales por su lejanía a la sociedad civil y por su abundancia en recursos para los proyectos mineros, situación que ha puesto en riesgo el sostenimiento social de los habitantes próximos a este tipo de proyectos, porque al tener como centro de vida su entorno natural y este al ser violentado por el desarrollo extractivo, estas poblaciones tienden a desplazarse a otros lugares para buscar mejores alternativas de manutención.

(...) Me sorprendió darme cuenta (...) de que realmente las industrias mineras se han vuelto una amenaza para los pueblos indígenas en todo el mundo. Parece ser que muchos de éstos están asentados sobre oro, plata, cobre y no sé cuántos valiosos minerales más, y ahora que hay nuevas tecnologías de extracción, la industria va sobre esas tierras. Y no es que los indígenas estén totalmente en contra de la minería, pero sí de que los despojen de sus territorios y de que las grandes empresas trasnacionales se lleven todas las ganancias. (Warnholtz 2013)

Como se puede apreciar, este tipo de fenómenos son un panorama común en todos los territorios que poseen las características ideales para el desarrollo de estos proyectos, pero en el caso de este apartado, se centrará la atención hacia algunos escenarios significativos acaecidos en algunos países de América Latina, tales como Perú, Chile y México.

En Perú, según investigaciones como las realizadas por Berterretche (2013) y Castro (2015), los principales afectados en cuanto a procesos de desplazamiento forzado por la implementación de este tipo de industria son las comunidades indígenas de esta nación:

En Bagua, departamento de Amazonas, Perú, en 2009, el entonces presidente Alan García justificó la expulsión de decenas de miles indígenas para favorecer empresas mineras por las necesidades del «desarrollo» que favorecería al conjunto de la población (...) El 5 de junio de ese año se produjo la masacre de Bagua, como parte del desalojo de aproximadamente 5.000 nativos aguarunas, huambishas y otros grupos étnicos amazónicos. (Berterretche 2013)

Es importante, a su vez, hacer hincapié en el favorecimiento que han dado gobiernos como el peruano, a las empresas mineras, generando procesos de
Desplazados legales o ilegales: una mirada desde los procesos extractivos en Colombia y contexto general de algunos países latinoamericanos

Angie Betancur Vargas Margarita María Pérez Osorno 
desmovilización social altamente violentos propiciados por los mismos organismos estatales.

Otros procesos de desalojo forzado a comunidades vulnerables a causa de la industria extractiva, dado en Perú lo demuestra El Instituto Francés de Estudios Andinos, (2015). León Castro, doctorando en ciencias sociales de esta corporación, en su investigación titulada Expansión minera en el Perú y desplazamiento de poblaciones campesinas: procesos e impactos evidenció las implicaciones territoriales causadas por la implementación de proyectos mineros en las comunidades agrarias, por medio de la elaboración de un paralelo entre los casos de Cuzco (con el proyecto Tintaya 1982) y Cajamarca (con el proyecto Galeno 2008). En esta investigación, demostró que en el proyecto Tintaya las reubicaciones realizadas en esta comunidad apuntan desde el año 1982, tras la expropiación de la colectividad Antaycama por parte de una compañía minera estatal que causó la reubicación de unas 86 familias, relocalización que en aquel entonces era legal e implicaba indemnización monetaria, la cual - según los testimonios recogidos en la investigación - no fue suficiente para la adquisición de nuevas parcelas y ha imposibilitado la recuperación de esta población tras la ejecución de este proceso. En el año 2002, a raíz de la privatización de la compañía, y debido a las querellas de los pobladores del lugar por los impactos socioambientales generados por la ejecución de esta labor, la comunidad logró un nuevo proceso de relocalización para un nuevo grupo de familias damnificadas tras la expansión de la mina, quienes también consideraban que las indemnizaciones realizadas no fueron justas y suficientes.

Otro ejemplo de la situación actual que vive Latinoamérica se da en Chile, país que encabeza la lista de las naciones suramericanas más influyentes en este tipo de industria:

Según Acevedo (2015), la ejecución de minería a cielo abierto ha ocasionado muerte y destrucción de varias comunidades en Chile, debido a las inundaciones y deslaves que este proceso económico ha generado, tanto en las zonas donde se lleva a cabo dicha labor, como en las áreas de influencia, situación que ha cobrado no solo la muerte de varias personas, sino también el desplazamiento forzado de poblaciones enteras.

Tal es el caso del proyecto minero Pascual Lama, el cual, según Terre Citoyenne y Association des Populations des Montagnes du Monde (2010) ha impactado de manera directa a las comunidades agrícolas de Alto del Carmen e indígenas huascoaltinas que habitan en la zona, las cuales se han visto directamente afectadas no solo en sus medios de producción y a nivel cultural, sino también en cuanto a ocupación territorial, ya que dicho proyecto ha tomado parte de sus suelos para llevar a cabo esta labor.

El contexto de los casos citados de cada uno de los países anteriores también se evidencia en algunas zonas mineras de México. Según Gonzales (2013), este país representa una de las cuatro naciones en América Latina que exteriorizan mayor conflictividad a causa de la explotación minera, situación relacionada con las implicaciones socio-ambientales provocadas por este tipo 
de industria en cuanto a contaminación, privación del recurso hídrico, debilidad en los procesos de consulta previa a las comunidades, conflictos por tierras, desplazamiento, alteración a los modos de producción, transgresión a los derechos humanos y ejecución de la labor de manera inadecuada en cuanto a las funciones de responsabilidad social e institucional. Actualmente, México cuenta con 26 casos relacionados a este tipo de conflictos y las cifras evidencian que, pese a adquirir un aumento del 3,9 por ciento del PIB para el año 2012 a causa de esta actividad, en los territorios donde se efectúa esta labor perdura la pobreza y altas condiciones de vulnerabilidad. Tales son los casos de Guerrero y San Luis Potosí.

Por los casos traídos a colación, se puede estimar que el fenómeno de desplazamiento forzado a raíz del desarrollo de la actividad minera es un hecho casi que inminente, ya sea de manera violenta, pacifica, inmediata o a través de los años. Este panorama se ha vuelto un lugar común en los escenarios de esta parte del continente, contexto que deja entrever el apoyo institucional de los gobiernos a costa de los propios y de su sostenibilidad territorial, solo por favorecer un escenario de explotación mineral y una economía de "exportación" que favorece más a los países industrializados que a los propios.

\section{Entre la turbación y el anhelo: el sector minero en el contexto colombiano y su relación con el despojo de tierras, migraciones y desplazamiento forzado}

Como bien se dice, "la desgracia de unos es la felicidad de otros", en este contexto, la "felicidad" se enmarca en las cifras nacionales de parte de la Inversión Extranjera Directa, quienes han encontrado un alto poderío en la titulación de tierras y concesiones ambientales para la explotación de manera legal de vastas hectáreas territoriales a múltiples multinacionales que han decidido "invertir" en el crecimiento económico del país, mientras comunidades enteras se lamentan de manera irreprochable por la pérdida de sus suelos, hábitats y culturas, a la par que son despojadas de sus entornos y obligadas a "salir" de sus lugares de origen.

Los contextos destacados en el numeral anterior no distan de las condiciones actuales de algunos territorios de Colombia, país que es considerado una de las principales naciones líderes en cuanto a la problemática social que representa este tipo de fenómenos:

Se está consolidando un despojo de tierra (a la par que) se está consolidando una inversión extranjera, especialmente en minería y palmicultura, que está relacionada con el desplazamiento forzado", dijo Jorge Rojas, director de la Consultoría para los Derechos Humanos y el Desplazamiento (CODHES) (...) Según Rojas, 32\% de las 280.000 personas desplazadas que se registraron en Colombia en 2010 provienen de zonas donde esas dos ac-
Desplazados legales o ilegales: una mirada desde los procesos extractivos en Colombia y contexto general de algunos países latinoamericanos

Angie Betancur Vargas Margarita María Pérez Osorno 

286.000 desplazados. ("El Universal” 2011)

Lo anterior deja entrever la situación actual de este país de una manera explícita y contundente, en donde se evidencia, según el número de nacionales desplazados a causa de la inserción de este tipo de industria, la importancia que el gobierno le ha otorgado a la generación y progreso de este sector. Según Censat-Agua Viva, CINEP/PPP, CETEC y Synergia, (2012), las metas del gobierno para el año 2019 son de duplicar la extracción de carbón, cuadruplicar la del oro y triplicar las zonas de contratos mineros, situación que ha llevado a numerosos sectores de la sociedad a evidenciar los impactos de esta política extractiva, entendiéndose que esta generará un gran número de disputas territoriales, altos porcentajes de desplazamientos, entre otros conflictos.

¿Cómo no se va a generar un incremento de manera paralela del sector minero y del número de conflictos territoriales, si el Estado no ha generado garantías de protección de derechos a las comunidades afectadas? Cuando se habla en Colombia de industria minera, sobresalen tres conceptos claves: conflicto armado, disputas territoriales y derechos humanos. Si bien es conocido a nivel mundial la relación de este país con los grupos al margen de la ley, el narcotráfico y la violencia territorial y que estos tres factores han marcado fuertemente la historia nacional, también es de comprensión popular que estos emergen en donde haya desatención del gobierno y lejanía estatal, contexto similar que se da en las zonas de interés minero: áreas generalmente distantes a las cabeceras municipales y de difícil acceso, situación no solo propicia para cualquier titular de esta industria, ya que cuenta con la libertad absoluta para ejercer la labor, debido a la carencia de organismos de control, sino también de los grupos al margen de la ley, quienes, igualmente, han encontrado en la minería una industria fuerte de financiamiento y generación de riquezas.

La suma de estos tres indicadores forma el contexto propicio para que emerjan disputas territoriales en zonas de interés minero: olvido del estado, zonas de difícil acceso y una labor generadora de múltiples ingresos, lo que da como resultado el quebrantamiento de los derechos humanos de los habitantes que viven en dichas regiones, quienes, debido a su escaso poder (comparando este con el del sector minero industrial y los grupos al margen de la ley), no tienen más remedio que aceptar las condiciones propuestas por estos organismos y admitir de manera "voluntaria" el desangre de sus suelos, recursos, culturas y derechos.

Autores como Castro (2015) señalan que, en el caso colombiano, del total de las personas desalojadas de sus territorios el $87 \%$ son a causa de la explotación minera. Dicho fenómeno ocasiona una fragilidad en cuanto al sostenimiento de las comunidades migrantes y en cuanto a los entornos en los que se asientan (que por lo general son las ciudades más cercanas), puesto que se desencadenan factores de riesgo como incremento de violencia, pérdida cultural y creación de barrios de invasión. 
A su vez, Bermúdez, Rodríguez y Roa (s.f.) manifiestan que una de las problemáticas que se vivencian en los territorios donde comienza a incursionar la minería es el cambio de la producción, que en la mayoría de los casos es agropecuaria, lo cual genera un gran impacto, ya que se intensifica el despojo de tierras de comunidades étnicas y campesinas, situación que no solo demuestra la vulneración y desconocimiento de los derechos de ciertos pueblos, sino también su destrucción a nivel físico y cultural. Las autoras señalan que no solo estas poblaciones padecen de despojo de sus tierras, sino también la denominada "privatización de los ríos y caminos", debido a la alta demanda de agua y energía que requieren este tipo de proyectos, situación que se convierte en un motivo más de vulneración colectiva de derechos, ya que si no se dispone de agua y tierra necesaria, los modos de vida de estos grupos se ven altamente afectados, lo que en su conjunto genera un deterioro de los estilos de vida tradicionales y de la salud pública.

Gonzáles (2010) asegura que, según anuncios del Banco Mundial, los reasentamientos involuntarios o los llamados desalojos forzados son el panorama común que se evidencia en el territorio colombiano, contexto que se ha generalizado y agravado tras el arribo de la producción minero-energética. Para dicho autor, factores como pobreza y marginalidad son las claras consecuencias de la falta de aplicación de convenios mundiales de protección y promoción de derechos humanos, patentizándose en las tasas de desplazamiento nacional, las cuales, en la mayoría de los casos, son precedidas por persecuciones e intimidaciones, acompañadas por terrorismo y represión:

La mayoría de los proyectos hidroeléctricos, extractivos, y algunos de los proyectos urbanos, industriales y de transporte, son realizables solamente si se desplaza a la gente de las tierras requeridas para el proyecto. Lo complejo del desplazamiento involuntario, es la perdida de las fuentes de ingresos, como tierras agrícolas, bosques, potreros, almacenes y otros recursos de producción, los cuales deben ser reemplazados (...) Con el desplazamiento involuntario se pueden perder bienes inmateriales o ganancias culturales de las comunidades por el impacto generado al cambiar de territorio; impacto que se evidencia en lo que los sociólogos denominan el rompimiento del tejido social. (Gonzáles 2010)

Según Censat-Agua Viva et al. (2012), en la base de datos del Centro de Investigación y Educación Popular (CINEP), entre los años 2000 y 2011, se registraron en total 104 luchas sociales relacionadas a la extracción minera en Colombia. Los ejemplos más destacados de los conflictos son:

- El proyecto Cerrejón, el cual se ubica en los municipios Barrancas, Fonseca y Distracción del Departamento de La Guajira, en el momento reporta grandes afectaciones en cuanto a la calidad de vida, enfermedad, contaminación ambiental, desplazamiento, debilitamiento del tejido social y detrimento cultura y territorial de la población residente en estos municipios.
Desplazados legales o ilegales: una mirada desde los procesos extractivos en Colombia y contexto general de algunos países latinoamericanos

Angie Betancur Vargas Margarita María Pérez Osorno 
- El proyecto Descanso Norte y La Loma, Drummond Company INC, ubicado en el departamento del Cesar, cuenta con conflictos relacionados a la contaminación, corrupción, persecución, violencia y asesinato de líderes sociales.

- El proyecto Angostura, Eco Oro Minerales Corp, ubicado en el Páramo de Santurbán, municipios de Vetas y California, actualmente cuenta con problemas relacionados a la contaminación ambiental y la ruptura del tejido social.

Con base a lo anterior, es importante destacar que la incursión de proyectos mineros en Colombia y su relación al incremento de las tasas de desplazamiento forzado del país se da en dos contextos: de parte de la minería ilegal ejercida por actores armados al margen de la ley y de parte de las multinacionales. A continuación se evidenciará este postulado por medio de la contextualización de ambos casos en diversos territorios del país, en donde se demuestran las cifras y ejemplos de migraciones forzadas, bien sea a causa de la minería legal o ilegal, pudiéndose notar los altos estragos sociales en materia de desalojos forzados que deja el accionar de esta labor en cualquier territorio.

\section{Casos de desplazamientos voluntarios a causa del accionar minero liderado por multinacionales de dicho sector}

A pesar de que Colombia cuenta con diversos tipos de normatividad y leyes que garantizan la protección de la comunidad ante el arribo de proyectos mineros en los territorios, los denominados "desplazamientos forzados", cuando se trata de este fenómeno acaecido por la incursión de una multinacional en determinado territorio, cambia de "razón social" o nombre y pasa a ser considerado "reasentamiento involuntario", es decir, si las personas migran debido a la incursión de este tipo de industria, bien sea por medio de acuerdos o no, no son consideradas desplazadas, sino desalojadas por motivos de interés estatal, situación que es contraria a si ocurre lo mismo, pero esta vez originado por el interés de los grupos al margen de la ley para apropiarse de dicho territorio con el fin de explotarlo en materia minero-energética. A continuación, los casos de dos departamentos nacionales que fueron "reasentados" bajo promesas falsas, acuerdos inconclusos e incluso expropiación territorial, situación que es "ilegal", si se toma en cuenta que son empresas que deben enmarcarse en el contexto legal vigente del país y cumplir con los derechos civiles de las poblaciones afectadas.

\section{Departamento de la Guajira}

Censat-Agua Viva et al. (2012) prueban otra de las problemáticas que vivencia el país en términos de desplazamientos forzados acarreados por la actividad minera. Según dicha organización, a más de 30 años de la puesta en 
marcha del denominado proyecto "El Cerrejón" en la Guajira, el cual cuenta con aproximadamente 70 mil hectáreas, este ha generado numerosas cifras de migraciones de parte de las comunidades étnicas que allí habitan. Tras la llegada del proyecto se comenzaron a ver sus implicaciones sociales, como la destrucción de sitios sagrados y cementerios. A través de los años, el pueblo Wayyú tuvo que soportar los desalojos de sus tierras producto de la expansión del proyecto, lo que generó la desaparición de pequeños asentamientos como: Chancletas, Tabaco, Tamaquito, entre otros. Si bien en el documento se menciona que algunos de estos se han recompensado monetariamente, ese monto de dinero recibido no compensa los daños culturales y tradicionales acaecidos sobre esta comunidad indígena. Para tener una aproximación en cifras, se cuenta que 70 mil indígenas de este departamento y del Cesar han sido desplazados para dar cabida a los denominados proyectos de desarrollo minero-energéticos y el $70 \%$ de la población Guajira cuenta con altos niveles de pobreza.

Para contextualizar un poco más sobre la situación que han padecido los habitantes de la Guajira, según Etnoterritorios (2011), la comunidad de Tabaco, corregimiento del municipio de Hato Nuevo, fue reubicada en La Cruz, tras la incursión de un proyecto minero, hoy en día, dicha colectividad padece temor a un nuevo desalojo tras la expansión de dicho proyecto, el cual ha engullido a su paso pueblos enteros de este departamento. Uno de sus líderes recuerda como desde el 2011 llegaron diversos tipos de maquinarias y hombres pertenecientes a la seguridad privada de dicha empresa norteamericana (Carbocol-Intercol) para llevar a cabo la expulsión de cerca de setecientos habitantes de su territorio y como ni los ruegos de la comunidad impidieron este proceso de reasentamiento involuntario:

(...) Nosotros vivíamos amamantándonos de la tierra, teníamos la seguridad alimentaria garantizada. Como en cualquier pueblo, en Tabaco había una escuela, una iglesia, un cementerio, y un puesto de salud. Era un pueblo tranquilo hasta 1997 cuando empezamos a recibir presiones de Carbocol-Intercor, para que abandonáramos el pueblo, pues se encontraba en las áreas de expansión del complejo minero. (...) Pronto se vieron rodeados por miembros de la seguridad privada y el temor creció entre la comunidad. Los vigilantes impusieron restricciones que impedian la tradicional caza nocturna y el ingreso a sus predios de laboreo. Por orden del municipio les fue cortada el agua y la electricidad, les retiraron plazas a los maestros, les fue desmantelado el centro de salud, les cerraron la oficina de Telecom, y hasta la iglesia católica destruyó unilateralmente parte del templo construido con recursos de la misma comunidad. (Etnoterritorios 2011)

(...) Frente a estas presiones algunos habitantes vendieron sus predios por sumas irrisorias estipuladas por los abogados compradores de la empresa (diez mil pesos por hectárea). En otros casos los mismos abogados se presen-
Desplazados legales o ilegales: una mirada desde los procesos extractivos en Colombia y contexto general de algunos países latinoamericanos

Angie Betancur Vargas Margarita María Pérez Osorno 
taban con órdenes de expropiación y ofrecían lo que querían a los dueños de las tierras. El dinero no les alcanzó para comprar ni siquiera una vivienda en otro lugar. Durante este período de presión encontraron asesinados a varios líderes de la comunidad sin que se supiese las causas. (Etnoterritorios 2011)

\section{Departamento del Cesar}

Según la Corporación Colombia informa (2016), comunidades como el Hatillo, Plan Bonito y Boquerón en el departamento del Cesar, Colombia, denunciaron su preocupación por los impactos acaecidos tras el desarrollo de la actividad minera en sus territorios, ya que ésta ha generado una ola de desplazamientos y desalojos de sus poblaciones:

Esas operaciones están causando una de los peores desplazamientos forzados, que es el desplazamiento forzado por contaminación (...) Las autoridades no se pronunciaron en favor de defender la integridad y los derechos de los pobladores. Comenta Johana Rocha. (Corporación Colombia informa 2016).

Plan Bonito, en el municipio El Paso, Cesar, es considerado el primer "pueblo fantasma" que ha dejado la extracción minera en este departamento, convirtiéndose esta en la primera localidad, según El Heraldo.com (2014), en padecer del proceso de reasentamiento con ofertas que como lo mencionan sus 800 habitantes no se han atendido. Este territorio, que históricamente ha sido considerado tierra de pescadores y agricultores, pasó a contar con áreas arruinadas y desoladas. Las 146 viviendas existentes fueron demolidas por sus propios habitantes como compromiso adquirido de estos con las empresas mineras del sector (Drummond, Prodeco y Colombian Natural Resources. A pesar de tener acuerdo de manera bilateral, estos solo se cumplieron de parte de los primeros, quienes solo han padecido hambre y desolación a causa del incumplimiento de las industrias asentadas en dicho sector.

El Heraldo.com (2014) también señala los casos de familias que se niegan a abandonar sus viviendas, sin embargo, aseguran que son conscientes que es una realidad que deben afrontar:

«La verdad es que esto es doloroso, es muy triste dejar mi casita, donde tuve y crié a mis nueve hijos», dice Isabel Ríos, una de las últimas en salir de Plan Bonito. (El Heraldo.com 2014)

A su vez, El Heraldo.com (2014), asegura por medio de su reportaje, que en dicho territorio ya no existe presencia de asentamientos humanos y que a partir de la década de los 90, cuando comenzó la incursión minera en este lugar, el contexto ambiental empezó a cambiar, primando montañas de carbón 
y de material de mina. De la misma manera, el diario periodístico trajo a colación los relatos de algunos de sus habitantes:

"Prácticamente fuimos sometidos a un desplazamiento forzoso», dijo la mujer que duerme en las noches en un cuarto de alquiler en La Jagua de Ibirico, pero que regresa en las mañanas a Plan Bonito, como resistiéndose al desarraigo. Y continúa relatando su drama. "A mí se me parte el alma cuando mi hija de seis años me dice que no quiere que le tumben su casita». (El Heraldo.com 2014)

«Los nativos dicen que antes vivían bien porque ellos salían a pescar, cultivaban la tierra para comer y no había contaminación, ahora ni en los ríos nos dejan meter porque todo es propiedad privada. Las minas se fueron apoderando del pueblo», sostuvo Carrillo. Como Plan Bonito, también deberán ser reubicados los corregimientos Boquerón, en La Jagua de Ibirico, y El Hatillo, en el municipio de El Paso. (El Heraldo.com 2014)

Estos son dos de los departamentos de carácter minero del país, los cuales han sido otorgados de parte del Estado a empresas mineras para ser explotados. Como se puede evidenciar en ambos casos, el interés de estas multinacionales es netamente territorial, ya que requieren de la máxima cantidad de hectáreas que les sea posible para poder explotar ampliamente los recursos y así adquirir mayor ganancia, situación que se hace imposible si hay presencia de población civil. En Colombia se cuenta con la denominada "consulta previa", la cual consiste en concertar con la comunidad las condiciones de acceso de este tipo de proyectos y, si esta está de acuerdo con su ejecución, se da cabida, si no, se debe buscar otro territorio a explotar, situación que se debe acatar, máxime si es territorio de carácter étnico, como son los dos casos mencionados en los ejemplos anteriores. El problema radica en que, a pesar de que existen "garantías constitucionales" que "protegen" los recursos patrimoniales de este tipo de comunidad, el gobierno, a su vez, es el "dueño" del suelo nacional, lo que indica, que si este considera que debe ser explotado para el bien común del país, estas comunidades deben ser reasentadas, por ende "obligadas" a salir de sus lugares de origen, lo que demuestra que, a pesar de tener un marco normativo bastante claro, existen falencias en cuanto a su ejecución y cumplimiento.

Si bien las empresas extractivas "otorgan" compensaciones monetarias a los dueños de estas tierras, dichas remuneraciones son mínimas y paupérrimas, impidiendo así que se dé un trato justo a las colectividades afectadas $\mathrm{y}$, si estas no acepten dichas "indemnizaciones", emergen de sus territorios sin nada. Fuera de esto, también se debe mencionar la presencia de fuerza pública y represalias que ejercen dichas multinacionales, las cuales, en algunos casos, acuden a las amenazas y amedrentamientos a las comunidades.

Existe otro factor más y es el desplazamiento que se da de manera "voluntaria". Como bien se ha podido constatar, en muchos casos las comunidades
Desplazados legales o ilegales: una mirada desde los procesos extractivos en Colombia y contexto general de algunos países latinoamericanos

Angie Betancur Vargas Margarita María Pérez Osorno 
no son obligadas a salir de parte de ningún actor, pero estas toman la decisión tras la pérdida de sus recursos y calidad de vida, contexto generado por la implementación de la labor minera en sus territorios. Así que, sea como sea, los habitantes adyacentes a proyectos mineros deben salir de sus lugares de origen. Como bien se mencionó antes, tras la incursión de un proyecto minero solo hay cabida para un sector: la labor minera o la comunidad.

La Organización de las Naciones Unidas y el Centro de las Naciones Unidas para los Derechos Humanos (s.f.) argumentan que es importante reconocer que los llamados "desplazamientos forzados" instauran graves transgresiones a un conjunto de derechos humanos reconocidos a nivel mundial, tales como: la alimentación, vivienda adecuada, salud, agua, educación, trabajo, seguridad del individuo y del hogar, derecho a un trato justo y libre de acciones crueles, inhumanas e indignas. Dicho esto, a nivel internacional está establecido y pactado que los procesos que incluyan desalojos se deben llevar a cabo bajo condiciones legales, en circunstancias excepcionales y respetando los derechos de las comunidades afectadas, y el máximo responsable de velar por que se cumplan condiciones propicias para un trato justo en cuanto a derechos humanos es el Estado:

Los Estados deben reconocer que la prohibición de los desalojos forzosos incluye el desplazamiento arbitrario que produce una alteración en la composición étnica, religiosa o racial de la población afectada. (Organización de las Naciones Unidas y el Centro de las Naciones Unidas para los Derechos Humanos, s.f.)

Por lo anterior, la Organización de las Naciones Unidas y el Centro de las Naciones Unidas para los Derechos Humanos (s.f.) enumeraron las principales características que deben tener en cuenta los desalojos para que se den de manera justa y garante de responsabilidad:

(...) a) estar autorizado por la ley; b) llevarse a cabo de acuerdo con el derecho internacional relativo a los derechos humanos; c) hacerse únicamente con el fin de promover el bienestar general; d) ser razonable y proporcional; e) estar reglamentado de tal forma que se garantice una indemnización $y$ rehabilitación completas y justas; $y f$ ) realizarse de acuerdo con las presentes directrices. La protección que ofrecen estos requisitos de procedimiento se aplica a todas las personas vulnerables y a los grupos afectados, independientemente de si poseen un título de propiedad sobre el hogar o los bienes en virtud de la legislación nacional. (Organización de las Naciones Unidas y el Centro de las Naciones Unidas para los Derechos Humanos, s.f.)

Pero con lo anterior solo queda una pregunta:, ¿Qué diferencia existe en Colombia entre el desplazamiento causado por las empresas y el generado por los grupos al margen de la ley, si ambos tipos de desplazamiento demuestran 
una ausencia parcial o en muchos casos absoluta de parte del gobierno, y de qué manera está cumpliendo este organismo con su deber de proteger los derechos de los suyos? A continuación se traerán a colación algunos contextos territoriales, en donde no sólo hay presencia de multinacionales en las comunidades, sino también de grupos ilegales al margen de la ley, situación que empeora el contexto de dichas poblaciones, ya que son dos los sectores interesados en sus tierras: las empresas y los actores armados ilegales.

\section{Casos de desplazamientos voluntarios a causa del accionar minero liderado por multinacionales de dicho sector y grupos armados al margen de la ley}

En Colombia existen dos caras de la minería: la legal y la ilegal. Se supone que la primera de estas es aquella que cumple con la normativa y leyes establecidas y se encuentra enmarcada en los requerimientos de carácter ambiental y social pactados a nivel internacional, y se dice que se supone, porque, como bien se pudo apreciar en el numeral anterior, este tipo de condiciones no se cumplen en la mayoría de los casos del país. Aquella considerada ilegal es el tipo de minería que no cuenta con los permisos y licencias necesarios para llevarse a cabo. En muchos casos, es ejecutada por medio de organismos ilegales como grupos al margen de la ley. Sin embargo, en algunos territorios, la presencia de ambos tipos de minería es más que evidente, lo que denota un olvido total del Estado y un doble impacto social y ambiental para este tipo de territorios.

Las empresas mineras y petroleras que operan en Colombia trabajan frecuentemente en áreas sometidas al conflicto armado y al desplazamiento forzado en tierras que han sido "abandonadas" debido a las presiones violentas a las que fueron sujetas las comunidades, o cuyos títulos han cambiado de mano durante el último decenio debido a la presión militar (...) (MiningWatch Canadá y Censat AguaViva 2009).

Lo anterior evidencia el cómo se vive en un entorno de carácter minero en el país, el cual se encuentra en constantes disputas territoriales de parte de las multinacionales, actores armados al margen de la ley y las comunidades mismas. En estos casos se excluye al Estado, porque este no da garantías a la comunidad, solo se limita a ofrecer su protección y soporte a las multinacionales en cuanto a la obtención de títulos y concesiones.

En la actualidad, la mayoría de departamentos de labor minera del país se encuentran enmarcados bajo estos dos tipos de minería, situación que podría explicar una de las razones por las cuales la nación encabeza la lista de población desplazada en el continente. Se contextualizan 6 territorios mineros, y su relación con las cifras de desplazamiento y ejecución de ambos tipos de minería.
Desplazados legales o ilegales: una mirada desde los procesos extractivos en Colombia y contexto general de algunos países latinoamericanos

Angie Betancur Vargas Margarita María Pérez Osorno 
Censat-Agua Viva et al. (2012) argumenta que territorios como La Toma en el municipio de Suárez, Cauca, actualmente se encuentra en una fuerte disputa territorial entre sus pobladores, las empresas mineras y el Estado. Si bien la minería se ha realizado en este sector de manera ancestral, representando esta no solo un ingreso laboral, sino también parte de su cultura e historia, hoy por hoy se ha convertido en el motivo de fuertes disputas y atropellos contra los derechos comunales y humanos de esta población, a pesar de que la Corte Constitucional reconoció que esta comunidad tiene prelación en cuanto a la explotación minera por ser considerado un pueblo ancestral. En los últimos veinte años, este territorio ha encarado una serie de fuertes altercados marcados por despojo y desplazamiento forzado, el cual se relaciona con la presencia de multinacionales que han desalojado a las comunidades para dar pie a los proyectos mineros.

Semana.com (2010), en uno de sus artículos, arguye que se han evidenciado fuertes denuncias de los pobladores de dicho municipio en los últimos años, relacionados a la actividad minera. Según los habitantes de dicho territorio, han recibido constantes amenazas los líderes mineros por parte de grupos armados al margen de la ley para abandonar el sector. En los informes consultados por la revista Semana, a la presencia de las FARC, se le han sumado otros grupos subversivos al territorio (Águilas Negras-Nueva Generación), los cuales por medio de retenes ilegales, intimidación con armas y coacciones se han encargado de anunciar el desalojo de los pobladores de sus suelos ancestrales:

El 4 de diciembre de 2009, a las 9:31 de la mañana, Licifrey Ararat, un líder minero del corregimiento de La Toma, recibió un mensaje de texto en su celular. "Hp no decidan por la comunida que si quieren en los recurs tienen

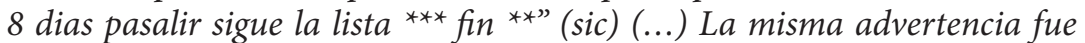
recibida por Yair Ortiz y Eduar Mina, dirigente del Consejo Comunitario de La Toma; Arley González, otro líder minero; Enrique Guetio, autoridad indígena, y Édwar Villegas, de la Central Unitaria de Trabajadores (CUT) en el Valle. (Semana.com 2010)

Como se puede apreciar, hay otro factor clave al momento de hablar de desplazamiento forzado generado por la industria minera y son los grupos armados al margen de la ley. Si bien estos desarrollan su actividad de una manera encubierta tras las repercusiones gubernamentales, también ejercen poder sobre los territorios ricos en materia mineral, inclusive, se ha encontrado que dichas organizaciones generan alianzas estratégicas con las mismas empresas mineras consideradas "legales" dentro de este sector industrial.

(...) Otras investigaciones y casos jurídicos han mostrado que algunas multinacionales han apoyado directa o indirectamente a los grupos parami- 
litares con el objeto de crear condiciones seguras para la inversión. En estos casos, los paramilitares funcionan como fuerzas irregulares para la consolidación territorial en los proyectos extractivos, sea que operen por su cuenta o bajo un entendimiento más explícito con las empresas transnacionales. (MiningWatch Canadá y Censat AguaViva 2009)

Mining Watch Canadá y CENSAT-AguaViva (2009) aseguran que en cada proceso de territorios mineros se marca una tendencia hacia el "desplazamiento forzado, concentración de la propiedad de las tierras, y presencia de actores armados", inclusive se ha evidenciado que la presencia de grupos delictivos se relaciona con el aprovechamiento de recursos minerales, bien sea de manera directa o indirecta. En Colombia existen varios territorios marcados por la violencia generada por este tipo de actividad, por ejemplo, Santander, Sur de Bolívar, Antioquia, Caldas y Tolima. La investigación realizada por las dos organizaciones mencionadas al principio del párrafo pretendió identificar el contexto de cada uno de estos territorios y reconocer que, de manera directa o no, las multinacionales encuentran una especie de beneficio, tras llevar a cabo sus proyectos en zonas con este tipo de características territoriales, particularizadas por el abandono estatal y azotadas por la violencia territorial.

Con base en el trabajo en campo realizado por Rettberg y Ortiz (2014), en 5 departamentos productores de oro en Colombia: Antioquia, Caldas, Nariño, Tolima y Santander, la actividad minera en la nación se distingue por dos tipos de conflictos básicamente: aquellos propiciados por los actores armados ilegales y los generados por la incursión de megaproyectos extractivos a cargo de multinacionales a determinadas comunidades.

Según Rettberg y Ortiz (2014), en primera estancia, los actores armados ilegales pueden tener vínculos con el desarrollo de este tipo de actividad de manera directa (participando en alguna fase de la cadena productiva de oro o actuando como mediadores en la compra de oro, con el fin de "lavar" el dinero ilegal por medio de la comercialización de este metal o el pago de regalías y distribución) o indirecta (mecanismos extorsivos ejercidos sobre los productores mineros).

A su vez, de acuerdo con la segunda causa evidenciada de conflictos generados por la minería, Rettberg y Ortiz (2014) destacan que la manera de asignación de este tipo de concesiones en el país ha generado que estos proyectos contiendan con las comunidades donde se llevan a cabo, generalmente en regiones, las cuales históricamente se han caracterizado por llevar a cabo operaciones de pequeña y mediana escala, tales como Marmato-Caldas, Sur de Bolívar y Buriticá-Antioquia, esto debido a las resistencias y oposiciones de parte de las comunidades a desplazar su modo de producción para dar cabida a estas empresas.

Con base en lo anterior, Rettberg y Ortiz (2014) también señalan que en otros territorios se presentan este tipo de disputas debido a que estos mismos
Desplazados legales o ilegales: una mirada desde los procesos extractivos en Colombia y contexto general de algunos países latinoamericanos

Angie Betancur Vargas Margarita María Pérez Osorno 
consideran la extracción minera como un método no viable para su desarrollo productivo, como es el caso en comunidades de tradición agrícola: Tolima, Norte de Nariño y Suroeste Antioqueño o en zonas de importancia ambiental como los casos del Páramo de Santurbán o el área de influencia del Macizo colombiano, los cuales representan ecosistemas de carácter estratégico y la incursión de proyectos mineros en estas últimas áreas ha generado tensión y disputas entre las comunidades de influencia de estas zonas.

Sin embargo, Rettberg y Ortiz (2014) argumentan que no todos los casos se han ejecutado por medio del empleo de violencia. En departamentos como Sur de Bolívar, Cauca, Norte de Nariño y Tolima se han evidenciado casos de amenazas e intimidaciones a las comunidades. En los tres primeros departamentos, se han tenido casos de desaparición o muerte de líderes locales y, al Sur de Bolívar, se le suman condiciones como el desplazamiento forzado.

En el documento objeto de análisis, realizado por MiningWatch Canadá y CENSAT-AguaViva (2009), se destacaron los siguientes distintivos de cada municipio objeto de estudio:

Sur del Bolívar: en la Serranía de San Lucas, ubicada en el Sur de Bolívar, opera la empresa B2Gold, territorio en el cual la Defensoría del Pueblo evidenció el gran interés de parte de grupos ilegales de controlar dicha zona y ejercer dominio sobre los minerales existentes. Según la investigación realizada por MiningWatch Canadá et al. (2009), el conflicto armado que se presenta en dicha región se genera por la apropiación territorial y la importancia estratégica de dicha área, situación que ha generado violaciones masivas de derechos humanos.

Según el Programa de Desarrollo y Paz del Magdalena Medio, entre 1994 y 2007, 116.453 personas de la región fueron desplazadas forzosamente, de las cuales 53.202 provenían de los municipios del Sur de Bolivar. Entre 1997 y 2007, 2.355 civiles del Magdalena Medio murieron por la violencia asociada a causas políticas; 380 de estos casos provenían del Sur de Bolívar. (MiningWatch Canadá y CENSAT-AguaViva 2009)

Santander: con respecto a este departamento, el conflicto armado ha generado la reubicación constante de la población ubicada en el área del proyecto extractivo denominada "Greystar" y sus proximidades. La Defensoría del Pueblo asegura que la presencia de paramilitares ha ocasionado este tipo de enfrentamientos y violencia.

Desde tiempos coloniales los municipios de California y Vetas, ubicados en el nororiente colombiano, en el departamento de Santander, han sido áreas tradicionalmente mineras. Durante muchos años, las áreas de alta montaña en la región permitieron a las filas guerrilleras desplazarse con cierta libertad, y tener una cierta autoridad de facto. Los habitantes de California y Vetas denuncian extorsiones por parte de grupos guerrilleros en 
forma de pagos mensuales. El conflicto armado ha resultado en reubicaciones frecuentes y forzadas (...) La incertidumbre y el temor de la población rural conforman un contexto favorable para la adquisición relativamente económica de propiedades por parte de terratenientes locales y especuladores. (MiningWatch Canadá y CENSAT-AguaViva 2009)

A lo anterior se le suma la situación que se ha vivido con la empresa canadiense Greystar Resources Ltd, la cual no solo tuvo que abandonar sus actividades durante el año 2000, después de llevar 5 años de labor en la zona, a causa del secuestro de uno de sus ejecutivos, sino también se asegura que, debido a la ausencia estatal en dicha área, la multinacional debió establecer relaciones de "conveniencia" con los grupos subversivos del lugar:

Según afirma la compañía: «En esta época, sí había una comunicación con las FARC... en estas zonas, no había Estado, eran ellos los que controlaban, aunque en California sí había una estación de policía». (MiningWatch Canadá y CENSAT-AguaViva 2009)

Antioquia y Caldas: en este primer departamento, las cifras demuestran que es uno de los territorios que evidencian mayor cantidad de casos de desplazamiento forzado a causa de conflictos territoriales generados por este tipo de proyectos. Estos desplazamientos se dan tanto por acción de paramilitares como por medio de la venta de tierras bajo coerción.

Según la Defensoría del Pueblo, la convergencia de tres factores ha forjado el conflicto armado en Antioquia y Caldas durante los últimos 20 años: la crisis cafetera; la rivalidad entre paramilitares y guerrilla por el dominio territorial y político de la región y el control del narcotráfico; y la influencia progresivamente mayor de empresas transnacionales con megaproyectos en la extracción de recursos. (MiningWatch Canadá y CENSATAguaViva 2009).

Tolima: MiningWatch Canadá y CENSAT-AguaViva (2009) dan a conocer en su informe que el departamento del Tolima se ha caracterizado por ser pieza clave en cuanto a territorios de conflicto armado desde el momento en el que se evidenció su alta riqueza minero-energética. Las estadísticas evidencian que, entre los años 2000 y 2003, cerca de 2000 personas fueros desplazadas de municipios como Ataco y Coyaima. A partir del año 2000 y 2001, tras el descubrimiento de su potencial petrolero, el Tolima atrajo la inversión de grandes multinacionales como Nexen, Ecopetrol y Petrobras.

Tras lo anterior, y retomando la pregunta realizada párrafos atrás sobre ¿qué diferencia existe entre el desplazamiento otorgado por las empresas y el generado por los grupos al margen de la ley?, se puede decir que - en cuanto a la práctica - ninguna, ya que ambas generan sí o sí un proceso de desplaza-
Desplazados legales o ilegales: una mirada desde los procesos extractivos en Colombia y contexto general de algunos países latinoamericanos

Angie Betancur Vargas Margarita María Pérez Osorno 
miento de la comunidad tras la pretensión de explotar los recursos minerales pertenecientes a dichas colectividades. Que los métodos empleados por dichos sectores tengan ciertas divergencias es otro asunto, pero no son distantes dichas diferencias, ya que, como se pudo evidenciar, ambos emplean mecanismos similares: amenazas, amedrentamientos, violencia (si es el caso), etc. La diferencia que existe es que las empresas poseen el apoyo de parte del gobierno, pues, como bien se pudo apreciar en uno de los ejemplos, este mismo se encargó de implementar acciones de coacción a la comunidad de manera indirecta - mediante el corte de servicios públicos - para que esta se fuera a otro lugar.

Existe otra diferencia en el marco de ambos tipos de desplazamientos y es que, en el caso de los generados por las multinacionales, estas (como se mencionó antes) otorgan a los dueños de los territorios cierto monto de dinero para que estos se reubiquen en otros sectores. El problema radica en que esta compensación en la mayoría de los casos es insuficiente y no representa montos significativos, lo que genera una brecha más grande de desigualdad y pobreza, porque al fenómeno de desplazamiento que padecen dichas colectividades se le suma los recursos ilimitados de estas para resurgir en otros lugares, contexto contrario al que se presenta con los desplazamientos generados por grupos ilegales al margen de la ley, debido a que estos u obligan a los pobladores a vender sus tierras a cualquier cifra o los despojan de manera inmediata de sus recursos.

Ante esto último, existe otro tema indispensable al momento de abordar el fenómeno de desplazamiento forzado y es el proceso de "restitución de tierras", el cual, según minagricultura (s.f.), constituye en el derecho que tienen las víctimas de este tipo de fenómenos a que sean devueltos sus predios, cuando estos han sido abandonados a causa del conflicto armado, con el fin de mejorar las condiciones socioeconómicas y alcanzar unos mejores estándares de calidad de vida de la población que ha sido víctima de este tipo de conflicto:

La restitución de tierras es una parte de la reparación integral de la Ley de Víctimas, por lo cual si una persona fue afectada por otro tipo de delitos podrá reclamar la indemnización, la rehabilitación, garantías de satisfacción y garantías de no repetición. (Minagricultura, s.f.)

Lo anterior no representa un panorama alentador, ya que se ha presentado que gran parte de las víctimas no pueden ejercer este derecho por carencia de pruebas o diferentes trabas administrativas existentes, pero de todas maneras surge otra pregunta: ¿Y qué ocurre con las comunidades que fueron desalojadas de sus predios y obtuvieron indemnizaciones insuficientes? Como se puede evidenciar, las garantías que ofrece el Estado ante cualquiera de estos casos son mínimas, empezando porque no se cercioran de que exista un debido proceso durante el proceso de titulación y concesión de licencias. 


\section{Palabras finales}

Se habla de desplazamiento forzado, porque, si bien muchas comunidades deciden "libremente" salir de sus territorios tras la implementación de proyectos mineros, no lo hacen con la voluntad de apartar lo dejado atrás para mejorar sus condiciones de vida en otros lugares, ya que las características propias de su territorio lo imposibilitan (entendiéndose con esto que la minería altamente desarrollada no es una característica propia de ninguna comunidad), sino para huir de los estragos que deja consigo la ejecución de este tipo de actividades extractivas. Para evitar un mayor detrimento a su salud física y mental, son obligados de manera directa o indirecta a hacer a un lado sus raíces, su cultura, sus medios de subsistencia, sus tierras, sus entornos porque ya no hay cabida en sus propios territorios para ellos.

(...) La Convención Americana sobre Derechos Humanos que reconoce que el desplazamiento incluye diferentes supuestos de hecho más allá del hecho de la violencia armada. En efecto, expone que el desplazamiento también se produce cuando se obliga a las personas a abandonar sus hogares por motivos legítimos. (Sarmiento 2015: 1)

Es desafortunado que los Estados den mayores garantías sobre el "uso" de las tierras a externos que a los propios, bajo el argumento de que el suelo es propiedad común y, por ende, se debe garantizar la primacía de los derechos de "expansión económica del país" que de los nacionales. Es por esto que algunas empresas mineras y los mismos gobiernos aseguran que tales desplazamientos no se realizan de manera forzada, puesto que no se ven patrones de violencia al momento de generar migraciones, garantizando que son altamente justificados puesto que están en vilo las relaciones económicas internacionales, la expansión financiera y el desarrollo del país; pero es evidente ya con lo analizado a lo largo del documento que estos desplazamientos se generan por varios motivos y causas, lo que deja en cuestión la función del gobierno de velar por los intereses de los ciudadanos. ¿Hasta qué punto es de interés común la expansión económica si se generan más procesos de empobrecimiento interno tras la ruptura de las relaciones sociales que trae consigo el fenómeno de desplazamiento forzado?

Según Berterretche (2013), "la principal causa de desigualdad se centra en la propiedad de la tierra”. En algunos países, prevalecen las desigualdades sociales debido a la propiedad estatal del territorio, y en otros, debido a los proyectos mineros, hidroeléctricos, mono-cultivos, los cuales generan altas repercusiones ambientales y sociales.

Hay condiciones que facilitan la desigualdad social. Tal vez una de ellas es la incapacidad que tienen los gobiernos de países como Colombia, de favorecer a los propios por encima de los beneficios monetarios de unos pocos. Como se puede evidenciar, esta nación se ha enfocado más en ser reconocida
Desplazados legales o ilegales: una mirada desde los procesos extractivos en Colombia y contexto general de algunos países latinoamericanos

Angie Betancur Vargas Margarita María Pérez Osorno 
internacionalmente como "productora de materia prima" que como defensora de sus territorios. La disputa por las tierras se ha convertido en uno de los grandes pleitos sociales entre los civiles y el Estado, lo que genera un panorama de disconformidad social, política, económica y territorial.

Si bien los factores que inciden en la movilidad humana son siempre multicausal, en la actualidad resulta evidente la incidencia que tiene en ella la percepción de la creciente desigualdad socioeconómica (...) Una motivación migratoria centrada en la búsqueda de mejor empleo comparativo como forma de concretar la aspiración a la prosperidad social y los beneficios de la riqueza o el desarrollo. (Jiménez 2010)

Castro (2015) señala que, tras el desplazamiento forzado que han padecido ciertos grupos sociales en Colombia a causa de la implementación de una economía minera, se han perdido otras actividades económicas importantes para el desarrollo del país, como la agricultura, lo que propicia una menor capacidad de sustento a largo plazo. Fuera de esto, también se generan estragos sociales a causa de la implementación de este tipo de modelo económico, como disminución de la calidad de vida tras la aparición de un número considerable de enfermedades que afectan la salud humana, tales como problemas cardiovasculares, renales y cáncer; lo que ocasiona el detrimento al derecho a una vida digna.

Es tan abrumador el alcance que ha tenido el modelo extractivista en Colombia que se ha dejado a un lado los prototipos económicos que representaron durante décadas el avance social y desarrollo de su país, como la agricultura y ganadería, por un modelo con características poco sustentables en cuanto a sus prácticas y consecuencias, tanto a nivel social como ambiental, el cual ha tenido como referencia las "ventajas" económicas que se podrían generar, y dejando a su paso una serie de conflictos territoriales, desigualdad, pobreza, desplazamiento y muertes:

Si bien es cierto que la distribución desigual de la tierra, la violencia histórica y la ausencia del estado han sido responsables de que la pobreza, el desplazamiento y el conflicto se acentúen tremendamente en el campo, la presencia de complejos mineros en los territorios colombianos puede hacer aún más difícil la vida de las comunidades rurales (...). Las cifras dejan ver este amargo panorama: Según Funtraenergética, en 2011, el 80\% de las violaciones a los derechos humanos que ocurrieron en Colombia se presentaron en los municipios mineros-petroleros (el 35\% del total nacional); el 87\% del desplazamiento forzado provenía de estos municipios y de quienes reciben regalías por producción minero-energética, mientras el 78\% de los crímenes contra sindicalistas, el $89 \%$ contra indígenas y el 90\% contra afrodescendientes se cometieron en las áreas donde el agro y la pesca se cambiaron, a las buenas o a las malas, por oro y petróleo. (Redacción vivir 2013) 
Como se puede denotar en el párrafo anterior, la ausencia del Estado ha facilitado en gran medida que el nivel de vulnerabilidad de este tipo de comunidades aumente, máxime, cuando no existen garantías que favorezcan la calidad de vida de los habitantes pertenecientes a este tipo de territorios. Al ser esta labor ejercida en zonas aisladas y de difícil acceso, los organismos de control no ejercen las acciones de vigilancia e inspección necesarias para este tipo de industria, lo que, por un lado, facilita una mayor libertad de parte de las empresas para llevar a feliz término su actividad, y por el otro, a los grupos al margen de la ley, para tomar partida de los recursos territoriales. ¿Pero cómo se puede asegurar que el Estado no ejerce las acciones de control y vigilancia necesarias ante la ejecución de este tipo de industria y que tampoco garantiza el cumplimiento de los derechos humanos y colectivos de estas comunidades? Sencillo, las cifras evidenciadas no solo en el párrafo preliminar, sino a lo largo del documento, lo dicen todo. A esto se le suma la tendencia del gobierno de hacerse "el de la vista gorda" ante este tipo de problemas sociales:

La impunidad ha estado vinculada estrechamenente con el desplazamiento forzado, esa es una de las conclusiones del informe "Una nación desplazada», que lanza hoy el Centro Nacional de Memoria Histórica (CNMH) (...) Prueba de lo anterior es que hasta el 2014, en la Fiscalía General de la Nación solo había 14.612 investigaciones activas por desplazamiento y un número bajo de denuncias, un recuento pobre frente a las dimensiones del flagelo. Además, las condenas emitidas en instancias judiciales contra los actores armados se han enfocado principalmente sobre delitos como el homicidio y la desaparición forzada. (Suárez 2015)

A esto se le suma la opinión pública de algunas instancias internacionales sobre el accionar del Estado colombiano ante este tipo de fenómenos. Según la Agencia EFE (2014), la Comisión Interamericana de Derechos Humanos (CIDH) expresó, el pasado 27 de octubre de 2014, su intranquilidad sobre el manejo de este gobierno ante la protección de los derechos de campesinos desplazados por la construcción de proyectos hidroeléctricos y concesión de megaproyectos. Esto se dio después de escuchar los reclamos de 21 organizaciones de este país y dio como resultado la solicitud ante el Estado sobre la información de las medidas que este ha tomado para restituir los derechos de las personas desplazadas y proteger su derecho a la tierra:

En este sentido, incidió en que 79.429 personas han sido desplazadas de la región conocida como el cañón del río Cauca, en Antioquia (noroeste), y que otras 3.200 fueron expulsadas de la zona de Córdoba, "porque había que abrirle paso a los megaproyectos».

Ante esta situación, la Agencia EFE (2014) asegura que el Estado contestó lo siguiente:
Desplazados legales o ilegales: una mirada desde los procesos extractivos en Colombia y contexto general de algunos países latinoamericanos

Angie Betancur Vargas Margarita María Pérez Osorno 

como personas desplazadas a las víctimas de la violencia y no a los campesinos desplazados para "proteger sus derechos" mediante el reasentamiento.

Pero ¿qué considera entonces el gobierno colombiano como población desplazada? ¿Solo a las víctimas de los actores armados ilegales? ¿Qué pasa con las víctimas de los proyectos mineros?

Como se pudo reflejar a lo largo del documento, una de las implicaciones más fuertes que trae consigo el desarrollo de la implementación de modelos de extracción minera en algunos países de América Latina ha sido el desplazamiento forzado, situación que deja entrever un panorama general de esta parte del continente, en donde se evidencia un desequilibrio social y de estructura interna débil de sus países. El error de algunos Estados latinoamericanos extractivos es confiar en un sistema de explotación de sus recursos que se encuentra en manos de empresas trasnacionales que solo desean explícitamente el mineral, careciendo de un sentido de pertenencia por el territorio en donde se da ese proceso de explotación.

En los casos estudiados, se puede observar cómo este modelo de extracción ha cobrado la estabilidad cultural, social, económica y territorial de centenares de personas, que de por sí cuentan con altos niveles de vulnerabilidad social por ser pertenecientes o a grupos étnicos o a comunidades campesinas, que al ser desplazados de sus tierras no tienen más opciones que limitarse a las pocas ayudas y colaboraciones del gobierno, institución misma que facilitó el proceso de expropiación de sus recursos y entornos, lo que se convierte en un asunto bastante paradójico.

Es importante, pues, que el país evalúe el costo-beneficio de la implementación de este tipo de actividad y las secuelas que ha dejado en el territorio nacional, con el fin de garantizar un desarrollo próspero de esta nación, ya que si se cuenta con un desequilibrio interno territorial, como lo demuestran los altos índices de desplazamiento forzado, no se podrá garantizar progreso ni social, ni político, ni económico, ni cultural.

Vale la pena resaltar y tener muy presente que el desarrollo de los proyectos mineros siempre repercute en las condiciones de vida de las comunidades aledañas, bien sea que estos procesos migratorios se den por presión directa de las industrias mineras o no, es un hecho, que estas forjan cambios en los modos de vida de las poblaciones, lo que las obliga a migrar, ya sea a territorios cercanos o no, para mejorar los contextos de vida deteriorados en sus propios entornos. 


\section{Bibliografía}

Acevedo P. (2015), Desplazamiento ambiental forzado, cambio climático y modelo extractivo, "Observatorio Ciudadano", 2014, disponible: http://business-humanrights.org/sites/ default/files/documents/Cambio\%20Clim\%C3\%A1tico\%20y\%20Desplazamiento\%20 Ambiental\%20OC\%20-\%20IWGIA\%20\%28FINAL\%29.pdf, consulta: 22.04.2016.

Agencia EFE (2014). CIDH expresa a Colombia inquietud por población desplazada por megaproyectos. "W Radio". 27.10.2014, disponiible: http://www.wradio.com.co/noticias/ internacional/cidh-expresa-a-colombia-inquietud-por-poblacion-desplazada-pormegaproyectos/20141027/nota/2481395.aspx, consulta: 29.06.2016.

Berterretche J. (2013), América Latina: desplazamientos forzosos de pobladores, "La haine. org", 26.02.2013, disponible en: http://www.lahaine.org/mundo.php/america-latinadesplazamientos-forzosos, fecha de consulta: 17.04.2016.

Bermúdez R., Rodríguez T. y Roa T. (s.f.) (2011), Mujer y minería: Ámbitos de análisis e Impactos de la minería en la vida de las mujeres-Enfoque de derechos y perspectiva de género. "Des-terres. Minées", s.f., disponible en: http://desterresminees.pasc.ca/wp-content/uploads/2015/11/ Bermudez-Rico-et-al-2011-Mujer_y_Mineria.pdf, fecha de consulta: 22.06.2016.

Blanco C. (2000), Las migraciones contemporáneas, "Papers Revista de Sociología", no 65, pp. 191-193.

Castro A, Ronderos R., Bernal F. (2015), Minería en Colombia: víctimas, causas y consecuencias del desplazamiento, en: revistas científicas de la universidad EA, vol. 5, no 1, pp. 28-35.

Censat-Agua Viva, CINEP/PPP, CETEC y Synergia (2012), Conflictividad en el sector minero-energético en Colombia, dosponible en: http://www.fundacionsynergia.org.co/pdf/ conflictominerodefinitivo.pdf, fecha de consulta: 23.06.2016.

Chaparro Ávila E., Salgado Pavés R. (2012), Sociedad, mercado y minería. Una aproximación a la responsabilidad social corporativa, Naciones Unidas, Santiago de Chile.

Clarin.com (2012), Fiebre del oro: la minería en auge y en jaque en Latinoamérica, "Clarin", 24.03.2012, disponible en: http://www.clarin.com/mundo/Fiebre-mineria-auge-jaqueLatinoamerica_0_670133075.html, fecha de consulta: 15.04.2016.

Corporación Colombia informa (2016), La Drummond sigue causando daños $y$ desplazamiento en el Cesar, "Colombia informa, agencia de comunicación de los pueblos", 29.01.2016, disponible en: http://www.colombiainforma.info/politica/medioambiente/3045-la-drummond-sigue-causando-danos-y-desplazamiento-en-el-cesar, fecha de consulta: 17.04.2016.

El Heraldo.com (2011), Minería deja el primer pueblo fantasma en Cesar, 08.06.2011, disponible en: http://www.elheraldo.co/cesar/mineria-deja-el-primer-pueblo-fantasmaen-cesar-155189, fecha de consulta: 23.06.2106.

"El Mundo" (2014), Desplazamiento forzado, una problemática en América Latina, "El Mundo", 15.05.2014, disponible en: http://www.elmundo.com/portal/noticias/internacional/desplazamiento_forzado_una_problematica_en_america_latina.php\#. V2wGwvnhDIU, fecha de consulta: 22.06.2016.

"El Universal" (2011), Minería y palmicultura, nuevas causas de desplazamiento en Colombia, "El Universal", 16.02.2011, disponible en: http://www.eluniversal.com.co/ cartagena/nacional/mineria-y-palmicultura-nuevas-causas-de-desplazamiento-encolombia-9783, fecha de consulta: 22.04.2016.
Desplazados legales o ilegales: una mirada desde los procesos extractivos en Colombia y contexto general de algunos países latinoamericanos

Angie Betancur Vargas Margarita María Pérez Osorno 
Etnoterritorios (2011), Tabaco, un pueblo devorado por la minería, "Reexistencias", 13.06.2011, disponible en: https://reexistencia.wordpress.com/2011/07/13/tabaco-unpueblo-devorado-por-la-mineria/, fecha de consulta: 24.06.2016.

Forest Peoples Programme (2003), La Minería y su grave impacto sobre los Bosques y los Pueblos, "Eco portal net", 14.08.2003, disponible en: http://www.ecoportal.net/TemasEspeciales/Mineria/La_Mineria_y_su_grave_impacto_sobre_los_Bosques_y_los_ Pueblos, fecha de consulta: 11.04.2016.

Gonzáles S. (2013), México, uno de los países de América Latina con más problemas con mineras, "La Jornada", 20.10.2013, disponible en: http://www.jornada.unam.mx/2013/10/20/ economia/024n1eco, fecha de consulta: 14.06.2016.

Gonzáles L. (2010), Desalojos forzados, reasentamientos involuntarios y derechos de las comunidades, "Colectivo de Abogados", 30.10.2010, disponible en: http://www. colectivodeabogados.org/Desalojos-forzados-reasentamientos

Grupo de Trabajo sobre Minería y Derechos Humanos en América Latina (2010), El impacto de la minería canadiense en América Latina y la responsabilidad de Canadá, Resumen Ejecutivo del Informe presentado a la Comisión Interamericana de Derechos Humanos, disponible en: http://www.cpalsocial.org/documentos/175.pdf, fecha de consulta: 28.04.2016.

Instituto Francés de Estudios Andinos (2015), ¿Migraciones consentidas, migraciones provocadas? Estudios de caso en la sierra y la selva peruana, 03.10.2015, disponible en: http://ifea.hypotheses.org/449

Jiménez R. (2010), Nuestra Patria debe ser el Universo: Propuestas para la Migración en una nueva Gobernanza Mundial en el Siglo XXI, Santiago de Chile, "Foro por una nueva Gobernanza Mundial - FnGM", disponible en: www.gobernanza-mundial.org, fecha de consulta: 13.04.2016.

Mendoza Piñeros A. (2012), El desplazamiento forzado en Colombia y la intervención del Estado, "Revista de Economía Institucional", vol. 14, no 26, pp. 169-202.

Minagricultura, (s.f.) (2016), Restitución de tierras, disponible en: https://www.minagricultura. gov.co/atencion-ciudadano/preguntas-frecuentes/Paginas/Restitucion-de-Tierras.aspx, fecha de consulta: 01.07.2016.

MiningWatch Canadá y Censat AguaViva (2009), Tierras y conflicto. Extracción de recursos, derechos humanos y la responsabilidad social empresarial: compañías canadienses en Colombia, Interpares, Canadá, disponible en: http://www.interpares.ca/es/publications/ pdf/Tierras_y_Conflicto.pdf, fecha de consulta: 23.06.2016.

Organización Internacional para las Migraciones (2006), Los términos clave de migración, disponible en: https://www.iom.int/es/los-terminos-clave-de-migracion, fecha de consulta: 22.04.2016.

Organización de las Naciones Unidas y Centro de las Naciones Unidas para los Derechos Humanos (s.f.) (2016), Principios básicos y directrices sobre los desalojos y el desplazamiento generados por el desarrollo. (Anexo I del Informe del Relator Especial sobre una vivienda adecuada, como parte del derecho a un nivel de vida adecuado), disponible en: http://www. ohchr.org/Documents/Issues/Housing/Guidelines_sp.pdf, fecha de consulta: 23.06.2016.

Redacción vivir, (2013), Minería y conflicto: aliados indeseables, "El Espectador”, 07.05.2013, disponible en: http://www.elespectador.com/noticias/nacional/80-de-violaciones-ddhh2011-fue-municipios-mineros-articulo-420511, fecha de consulta: 22.04.2016.

Rettberg A, Ortiz J. (2014), Conflicto Dorado: Explorando la relación entre minería de oro, conflicto armado y criminalidad en Colombia, Informe final del proyecto del 
grano al anillo: Análisis de la cadena de valor del oro y su relación con la ilegalidad y el conflicto armado en Colombia financiado por el Centro de Estudios sobre Seguridad y Drogas (CESED) de la Universidad de los Andes, 06.20.2014, disponible en: http:// www.environmentalpeacebuilding.org/library/show/libraryitem-709, fecha de consulta: 23.06.2016.

Rinde Cuentas (2015), Desde Canadá hasta Argentina, un año de grandes desastres mineros en toda América, "No a la mina, la montaña sigue en pie gracias a su gente" 13.12.2015, disponible en: http://www.noalamina.org/latinoamerica/general/item/14942-desde-canadahasta-argentina-un-ano-de-grandes-desastres-mineros-en-toda-america, fecha de consulta: 15.04.2016.

Sarmiento J. (2015), Desplazamiento interno por proyectos de desarrollo, "Revista de Derecho", no 44, pp. 7-10.

Semana (2010), Oro, violencia y muerte en Suárez, Cauca, "Semana", 08.04.2010, disponible en: http://www.semana.com/nacion/problemas-sociales/articulo/oro-violencia-muerte-suarezcauca/115274-3, fecha de consulta: 23.06.2016.

Semana (2015), Colombia conserva el deshonroso título del segundo país con más desplazados, "Revista Semana", 06.05.2015, disponible en: http://www.semana.com/nacion/articulo/ colombia-es-el-segundo-pais-con-mas-desplazados/426628-3, fecha de consulta: 22.06.2016.

Suárez J. (2015), Desplazamiento en Colombia, impune, "El Espectador", 06.10.2015, disponible en: http://www.elespectador.com/noticias/nacional/desplazamiento-colombiaimpune-articulo-591211, fecha de consulta: 24.06.2016.

Tejada A. (2010), Estudio de poblaciones en situación de desplazamiento a causa de proyectos de infraestructura en la República Dominicana, "Revista Tend. Retos", vol. 15, pp. 33-47.

Terre cytoyenne y Association des Populations des Montagnes du Monde (2010), Pascual Lama, Controvertido proyecto minero pone en riesgo los glaciares, el agua y el desarrollo agrícola en el valle del río huayco, norte de Chile, disponible en: http://www.almedio.fr/uploads/media/ ECADIM_Pascualama_portada.pdf, fecha de consulta: 14.06.2016.

Vanguardia.com (2009), Diez principales causas de desplazamiento en el país, "Vanguardia. com" 04.07.2009, disponible en: http://www.vanguardia.com/historico/32565-diez-principalescausas-de-desplazamiento-en-el-pais, fecha de consulta: 15.04.2016.

Warnholtz M. (2013), Mineras vs indígenas: en todo el mundo pasa lo mismo, "No a la mina, la montaña sigue en pie gracias a su gente", 01.03.2013, disponible en: http://www. noalamina.org/mundo/info-global/item/11372-mineras-vs-indigenas-en-todo-el-mundopasa-lo-mismo, fecha de consulta: 15.04.2016.
Desplazados legales o ilegales: una mirada desde los procesos extractivos en Colombia y contexto general de algunos países latinoamericanos

Angie Betancur Vargas Margarita María Pérez Osorno 